\title{
Differences in radiological and functional outcomes between cervical spondylotic myelopathy and ossification of the posterior longitudinal ligament after multi-level laminoplasty
}

\section{Dongwoo Yu}

Yeungnam University School of Medicine and College of Medicine

\section{Sang Woo Kim}

Yeungnam University School of Medicine and College of Medicine

Ikchan Jeon ( jicns@ynu.ac.kr)

Yeungnam University Medical Center https://orcid.org/0000-0002-1293-2724

Research article

Keywords: Cervical spondylotic myelopathy, ossification of the posterior longitudinal ligament, laminoplasty, cervical spine, outcome

Posted Date: May 7th, 2020

DOI: https://doi.org/10.21203/rs.3.rs-24947/v1

License: (c) (i) This work is licensed under a Creative Commons Attribution 4.0 International License.

Read Full License 


\section{Abstract \\ Objective}

The purpose of this study was to compare the radiological and functional outcomes between patients with cervical spondylotic myelopathy (CSM) and ossification of the posterior longitudinal ligament (OPLL) after multi-level laminoplasty.

\section{Methods}

This study included 75 patients ( 32 with CSM and 43 with OPLL) with preserved cervical sagittal balance who underwent multi-level laminoplasty for cervical myelopathy. The radiological outcomes were analyzed using the following parameters: $\mathrm{C} 2-\mathrm{C} 7 \mathrm{Cobb}$ angle in neutral (C27AN), flexed (C27AF), and extended (C27AE) neck postures; $\mathrm{C} 2-\mathrm{C} 7$ range of motion (C27ROM); T1 slope (T1S); and C2-C7 sagittal vertical axis (C27SVA). The functional outcomes were analyzed using the modified Japanese Orthopedic Association ( $\mathrm{mJOA}$ ) score, Nurick grade, and recovery rate. The radiological and functional outcomes between the two groups were evaluated 12-months postoperatively.

\section{Results}

C27AF, C27ROM, and C27SVA in the CSM group and C27ROM in the OPLL group decreased significantly $(p<0.05)$. There was a significant difference in $\triangle \mathrm{C} 27 \mathrm{SVA}$ between the two groups $(9.41 \pm 17.06 \mathrm{~mm}$ vs. $1.10 \pm 17.15 \mathrm{~mm}, p<0.05)$. However, there were no significant intra- or intergroup changes and differences in C27AN ( $p>0.05)$. The functional outcomes including mJOA score $(p=0.251)$, Nurick grade $(p=0.316)$, and recovery rate $(p=0.435)$ showed no significant intergroup differences.

\section{Conclusions}

Although there were no significant differences in functional outcomes between the two groups, the CSM group showed a greater deterioration in sagittal balance with an increase of C27SVA than the OPLL group after multi-level laminoplasty.

\section{Background}

Laminoplasty is an effective surgical method for the treatment of degenerative cervical myelopathy. It was developed to avoid the problems associated with laminectomy, such as postoperative kyphotic change, segmental instability, and perineural adhesions [1]. Nevertheless, one of the morbidities after laminoplasty is the postoperative loss of cervical lordosis and straightening of the cervical spine. This postoperative kyphotic change of the cervical curvature has a negative effect on clinical outcome, and 
maintaining postoperative cervical lordosis is important for spinal cord decompression as a result of the posterior shift of the spinal cord [2].

Recently, the T1 slope (T1S) and C2-C7 sagittal vertical axis (C27SVA) have emerged as predictors of kyphotic alignment change after laminoplasty. Kim et al. [3] reported that a preoperative higher T1S is a risk factor for postoperative kyphotic change in ossification of the posterior longitudinal ligament (OPLL). Lin et al. [4] reported that a preoperative higher T1S and longer C27SVA have a higher risk of postoperative cervical malalignment in cervical spondylotic myelopathy (CSM). Many previous studies have examined the relationship between preoperative radiological parameters and changes in sagittal alignment after laminoplasty.

Thus far, the majority of previous studies have focused on the overall postoperative changes in patients with cervical myelopathy without distinguishing between CSM and OPLL. Only few reports have compared the outcomes between CSM and OPLL after laminoplasty. In this study, we analyzed the radiological and functional outcomes between patients with CSM and OPLL who had preserved preoperative sagittal balance and similar neurological status after multi-level laminoplasty.

\section{Methods}

\section{Participants}

This retrospective study enrolled consecutive patients with preserved lordotic cervical curvature and no dynamic instability who underwent cervical laminoplasty for cervical myelopathy caused by CSM or OPLL between February 2013 and October 2018 in a single spine center. Cervical myelopathy was confirmed based on clinical symptoms, neurological examination, electrophysiological study, and magnetic resonance imaging (MRI). All patients underwent preoperative computed tomography (CT), MRI, and lateral radiographs including dynamic views. Patients with spinal cord tumors, infections, traumatic cervical cord injuries, syringomyelia, cervical spine deformities, myelitis, and prior cervical surgeries were excluded. We also excluded patients in whom the $\mathrm{C} 7$ vertebral body was not observed in the preoperative cervical lateral radiography. All patients underwent posterior open-door laminoplasty using a plate system (CENTERPIECE plate, Medtronic Sofamor Danek, Memphis, TN, USA) and were followed up for 12 months. All patients wore a Philadelphia neck collar for 2 months postoperatively. The collected demographic data included age on the day of surgery, sex, duration of symptoms, and body mass index. All clinical and radiological data were obtained and reviewed from electronic charts after approval by the Institutional Review Board.

\section{Radiological Assessment}

Lateral radiographs in neutral and dynamic neck postures were acquired sequentially. Dynamic radiographs were taken by asking patients to stretch their neck in complete flexion and extension. Cervical sagittal balance was evaluated with various radiographic parameters including $\mathrm{C} 2-\mathrm{C} 7$ sagittal 
vertical axis (C27SVA); T1 slope (T1S); C2-C7 Cobb angle (C27AN in neutral, C27AF in flexed, and C27AE in extended neck postures); and $\mathrm{C} 2-\mathrm{C} 7$ range of motion (C27ROM). C27SVA was measured as the horizontal distance between the $\mathrm{C} 2$ plumb line and the posterior-superior aspect of C7. C27AN was measured as the sagittal Cobb angle of the lower endplate of $\mathrm{C} 2$ and $\mathrm{C} 7$ in the natural position. C27AF and C27AE were measured in the same way on dynamic radiographs. The measurement of radiological parameters is presented in Fig. 1. Lordosis was recorded as a positive value and kyphosis was recorded as a negative value. C27ROM was measured as the difference between C27AE and C27AF, while T1S was measured as the angle between the horizontal plane and the superior T1 endplate in the preoperative sagittal view of CT. Postoperative loss of cervical lordosis was defined as the difference between preoperative C27AN and postoperative C27AN. All measurements were performed by two independent investigators using digitalized radiographic data stored on a computer software system (PACS M6, INFINITT Healthcare, Seoul, Korea). The final radiological parameters were confirmed using the average of the two investigator's measurements.

\section{Assessment Of Functional Outcome}

The preoperative severity of myelopathy and surgical outcome were evaluated using a modified Japanese Orthopedic Association (mJOA) score and Nurick grade. The mJOA score is an 18-point scale that addresses upper (5 points) and lower (7 points) extremity motor function, sensation (3 points), and micturition (3 points). The Nurick grade is classified into five grades as follows: 0 , signs or symptoms of root involvement but with no evidence of spinal cord disease; 1 , signs of spinal cord disease but no difficulty in walking; 2 , slight difficulty in walking that does not prevent full-time employment; 3 , difficulty in walking that prevents full-time employment or the ability to perform housework but is not severe enough to require assistance when walking; 4, able to walk with assistance; and 5, chair bound or bedridden. The recovery rate was calculated using the formula established by Hirabayashi [postoperative - preoperative mJOA score/18 - preoperative mJOA score × $100(\%)][5]$.

\section{Statistical analysis}

Student's $t$-test for parametric continuous variables and Mann-Whitney $\mathrm{U}$ test for non-parametric continuous variables were used to compare the two population means. The chi-square test was used to assess the relationship between categorical variables, and repeated measures analysis of variances (ANOVA) for parametric continuous variables changing over time was used to compare the two population means. The Pearson correlation coefficient $(r)$ was used to assess the relationship between the parametric continuous variable. The value of $r$ ranged from +1 to -1 and was defined as a strong correlation between \pm 0.50 and \pm 1.00 , as medium correlation between \pm 0.30 and \pm 0.49 , and as small correlation below \pm 0.29 . The inter-observer reliabilities for radiological parameters were measured using intra-class correlations (ICC; two-way mixed model with consistency agreement; 95\% confidence interval). ICC values were defined as poor agreement for $0.00-0.20$, fair agreement for $0.21-0.40$, moderate agreement for $0.41-0.60$, good agreement for $0.61-0.80$, and very good agreement for $0.81-1.0$. 
Statistical analysis was carried out using SPSS version 25.0 software (SPSS Inc., Chicago, Illinois), and probability values of $<0.05$ were considered statistically significant.

\section{Results}

\section{Demographic data}

Among the 95 patients, 20 patients were excluded owing to traumatic cervical cord injury $(n=10)$, prior cervical surgery $(n=4)$, follow-up loss $(n=4)$, and inappropriate radiographs $(n=2)$. The final analysis was included 75 patients with $32 \mathrm{CSM}$ (group A) and 43 OPLL (group B) patients. There were no statistically significant differences in age (64.50 \pm 11.99 vs. $63.60 \pm 10.35, p=0.727)$ and sexual distribution ( 25 men and 7 women vs. 29 men and 14 women, $p=0.308$ ) between groups $A$ and $B$. The extent of laminoplasty was $2.56 \pm 0.56$ levels in group $A$ and $2.70 \pm 0.56$ levels in group $B(p=0.305)$. However, group A showed a significantly lower BMI than group B $(23.75 \pm 3.41$ vs. $25.32 \pm 3.24, p=0.046)$. Detailed data are presented in Table 1.

Table 1

Demographic and clinical data

\begin{tabular}{|lllll|}
\hline & Group A (CSM) & Group B (OPLL) & Total (Group A+B) & $p^{\prime}$ value $^{+}$ \\
\hline No. of patients & 32 & 43 & 75 & \\
\hline Sex (men:women) & $25: 7$ & $29: 14$ & $54: 21$ & 0.308 \\
\hline Age (years) & $64.50 \pm 11.66$ & $63.60 \pm 10.35$ & $63.99 \pm 10.86$ & 0.727 \\
\hline BMI & $(47-82)$ & $(45-84)$ & $(45-84)$ & \\
\hline Extent of laminoplasty & $23.75 \pm 3.41$ & $25.32 \pm 3.24$ & $24.65 \pm 3.38$ & 0.046 \\
\hline $\begin{array}{l}\text { Duration of symptom } \\
\text { (month) }\end{array}$ & $(18.73-32.05)$ & $(17.07-34.05)$ & $(17.07-34.05)$ & \\
\hline $\begin{array}{l}\text { CSM cervical spondylotic myelopathy; OPLL ossification of posterior longitudinal ligament; BMI body } \\
\text { mass index; }{ }^{+} \text {between groups A and B }\end{array}$ & $(2-3)$ & $(2-4)$ & $2.64 \pm 0.56$ & 0.305 \\
\hline
\end{tabular}

\section{Radiological outcome}

1. Preoperative radiological parameters 
Preoperative radiological parameters were analyzed between groups $A$ and $B$. There was a significant difference in preoperative $\mathrm{C} 27 \mathrm{ROM}\left(46.53^{\circ} \pm 15.18^{\circ}\right.$ vs. $\left.37.87^{\circ} \pm 13.18^{\circ}, p=0.01\right)$. However, there were no significant differences in C27AN $\left(17.20^{\circ} \pm 10.4^{\circ}\right.$ vs. $\left.15.22^{\circ} \pm 10.60^{\circ}, p=0.423\right)$; C27AF $\left(16.99^{\circ} \pm 8.54^{\circ}\right.$ vs. $\left.12.94^{\circ} \pm 9.20^{\circ}, p=0.059\right) ; \operatorname{C} 27 \mathrm{AE}\left(29.53^{\circ} \pm 11.49^{\circ}\right.$ vs. $\left.24.88^{\circ} \pm 12.84^{\circ}, p=0.109\right) ; \mathrm{T} 1 \mathrm{~S}\left(23.39^{\circ} \pm 7.31^{\circ} \mathrm{vs}\right.$. $\left.23.99^{\circ} \pm 8.32^{\circ}, p=0.744\right)$; and preoperative C27SVA (17.93 $\pm 10.57 \mathrm{~mm}$ vs. $\left.22.65 \pm 13.41 \mathrm{~mm}, p=0.104\right)$. Preoperative radiological data are presented in Table 2.

Table 2

Pre- and postoperative radiological parameters in groups $A$ and $B$

\begin{tabular}{|c|c|c|c|c|}
\hline & Group A (CSM) & Group B (OPLL) & Total (Group A + B) & $p$ value $^{+}$ \\
\hline \multicolumn{5}{|l|}{ Preoperative } \\
\hline C27AN $\left({ }^{\circ}\right)$ & $17.20 \pm 10.40$ & $15.22 \pm 10.60$ & $16.06 \pm 10.49$ & 0.423 \\
\hline C27AF $\left({ }^{\circ}\right)$ & $16.99 \pm 8.54$ & $12.94 \pm 9.20$ & $14.70 \pm 9.08$ & 0.059 \\
\hline C27AE $\left({ }^{\circ}\right)$ & $29.53 \pm 11.49$ & $24.88 \pm 12.84$ & $26.86 \pm 12.42$ & 0.109 \\
\hline $\operatorname{C27ROM}\left({ }^{\circ}\right)$ & $46.53 \pm 15.18$ & $37.87 \pm 13.18$ & $41.57 \pm 14.62$ & 0.010 \\
\hline $\operatorname{T1S}\left({ }^{\circ}\right)$ & $23.39 \pm 7.31$ & $23.99 \pm 8.32$ & $23.72 \pm 7.86$ & 0.744 \\
\hline C27SVA (mm) & $17.93 \pm 10.57$ & $22.65 \pm 13.41$ & $20.64 \pm 12.43$ & 0.104 \\
\hline \multicolumn{5}{|c|}{ Postoperative (12 months) } \\
\hline C27AN $\left({ }^{\circ}\right)$ & $13.08 \pm 13.96$ & $11.29 \pm 11.51$ & *12.05 \pm 12.55 & 0.547 \\
\hline C27AF $\left({ }^{\circ}\right)$ & *10.75 49.88 & $12.27 \pm 9.39$ & $11.62 \pm 9.57$ & 0.499 \\
\hline C27AE $\left({ }^{\circ}\right)$ & $23.37 \pm 14.56$ & $19.82 \pm 11.38$ & $\star 21.34 \pm 12.86$ & 0.240 \\
\hline $\operatorname{C27ROM}\left({ }^{\circ}\right)$ & $\star 32.24 \pm 12.94$ & $\star 31.78 \pm 10.84$ & $\star 32.83 \pm 11.76$ & 0.313 \\
\hline T1S $\left({ }^{\circ}\right)$ & $25.46 \pm 5.25$ & $23.18 \pm 5.11$ & $24.13 \pm 5.26$ & 0.058 \\
\hline C27SVA (mm) & $\star 27.34 \pm 15.30$ & $23.75 \pm 12.53$ & $\star 25.29 \pm 13.80$ & 0.268 \\
\hline \multicolumn{5}{|c|}{$\begin{array}{l}\text { CSM cervical spondylotic myelopathy; OPLL ossification of posterior longitudinal ligament; C27AN } \\
\text { C2-7 Cobb angle in neutral; C27AF C2-7 Cobb angle in flexion; C27AE C2-7 Cobb angle in extension; } \\
\text { C27ROM C2-7 range of motion; T1S T1 slope; C27SVA C2-7 sagittal vertical axis; }{ }^{+} \text {between groups A } \\
\text { and B; * Significant difference compared to preoperative data }(p<0.05)\end{array}$} \\
\hline
\end{tabular}

2. Postoperative radiological parameters

Postoperative radiological parameters were analyzed between groups $A$ and $B$. There were no significant differences in postoperative radiological parameters including C27AN $\left(13.08^{\circ} \pm 13.96^{\circ}\right.$ vs. $11.29^{\circ} \pm$ $\left.11.51^{\circ}, p=0.547\right)$; $\mathrm{C} 27 \mathrm{AF}\left(10.57^{\circ} \pm 9.88^{\circ}\right.$ vs. $\left.12.27^{\circ} \pm 9.39^{\circ}, p=0.499\right)$; C27AE $\left(23.37^{\circ} \pm 14.56^{\circ} \mathrm{vs}\right.$. $\left.19.82^{\circ} \pm 11.38^{\circ}, p=0.240\right)$; C27ROM $\left(32.24^{\circ} \pm 12.94^{\circ}\right.$ vs. $\left.31.78^{\circ} \pm 10.84^{\circ}, p=0.313\right)$; T1S $\left(25.46^{\circ} \pm 5.25^{\circ}\right.$ vs. $\left.23.18^{\circ} \pm 5.11^{\circ}, p=0.058\right)$; and C27SVA $(27.34 \pm 15.30 \mathrm{~mm}$ vs. $23.75 \pm 12.53, p=0.268)$. There were 
statistically significant differences in C27AF, C27ROM, and C27SVA of group A and in C27ROM of group $B$ between the pre- and postoperative data $(p<0.05)$. Postoperative radiological data are presented in Table 2.

3. Comparison of the changes $(\Delta)$ of radiological parameters for 12 months between the two groups

There was a significant difference in $\triangle$ C27SVA $(9.41 \pm 17.06$ vs. $1.10 \pm 17.15, p=0.041)$ between groups $A$ and $B$; however, there were no significant differences in radiological parameters including $\triangle \mathrm{C} 27 \mathrm{AN}(p=$ $0.959), \triangle \mathrm{C} 27 \mathrm{AF}(p=0.088), \Delta \mathrm{C} 27 \mathrm{AE}(p=0.787), \triangle \mathrm{C} 27 \mathrm{ROM}(p=0.150)$, and T1S $(p=0.106)$ between two groups. Comparison of radiological changes $(\Delta)$ for 12 months between two groups is presented in Table 3.

Table 3

Comparison of the changes $(\Delta)$ of radiological parameters for 12 months between groups $A$ and $B$

\begin{tabular}{|c|c|c|c|c|}
\hline & Group A (CSM) & Group B (OPLL) & Total (Group A + B) & $p$ value $^{+}$ \\
\hline$\triangle \mathrm{C} 27 \mathrm{AN}\left({ }^{\circ}\right)$ & $-4.12 \pm 17.24$ & $-3.93 \pm 15.19$ & $-4.01 \pm 15.98$ & 0.959 \\
\hline$\triangle \mathrm{C} 27 \mathrm{AF}\left({ }^{\circ}\right)$ & $-6.24 \pm 15.24$ & $-0.71 \pm 12.42$ & $-3.08 \pm 13.87$ & 0.088 \\
\hline$\triangle \mathrm{C} 27 \mathrm{AE}\left({ }^{\circ}\right)$ & $-6.16 \pm 17.88$ & $-5.06 \pm 17.09$ & $-5.53 \pm 17.32$ & 0.787 \\
\hline$\triangle \mathrm{C} 27 \mathrm{ROM}\left({ }^{\circ}\right)$ & $-12.28 \pm 19.90$ & $-6.10 \pm 16.83$ & $-8.74 \pm 18.33$ & 0.150 \\
\hline$\Delta \mathrm{T} 1 \mathrm{~S}\left({ }^{\circ}\right)$ & $2.08 \pm 7.13$ & $-0.85 \pm 8.05$ & $0.40 \pm 7.75$ & 0.106 \\
\hline$\triangle \mathrm{C} 27 \mathrm{SVA}(\mathrm{mm})$ & $9.41 \pm 17.06$ & $1.10 \pm 17.15$ & $4.64 \pm 17.49$ & 0.041 \\
\hline \multicolumn{5}{|c|}{$\begin{array}{l}\text { CSM cervical spondylotic myelopathy; OPLL ossification of posterior longitudinal ligament; C27AN } \\
\text { C2-7 Cobb angle in neutral; C27AF C2-7 Cobb angle in flexion; C27AE C2-7 Cobb angle in extension; } \\
\text { C27ROM C2-7 range of motion; T1S T1 slope; C27SVA C2-7 sagittal vertical axis; }{ }^{+} \text {between groups A } \\
\text { and B }\end{array}$} \\
\hline
\end{tabular}

4. Relationships between preoperative factors (age, C27ROM, and T1S) and changes $(\Delta)$ of radiological parameters during the postoperative 12 months

In preoperative age, there were significant correlations with $\triangle \mathrm{C} 27 \mathrm{AF}$ in group A $(r=0.391)$; and $\triangle \mathrm{C} 27 \mathrm{AF}(r$ $=0.293$ ) and $\triangle$ C27SVA $(r=-0.236)$ in total patients (group A $+B$ ), respectively. In preoperative C27ROM, there were significant correlations with $\triangle \mathrm{C} 27 \mathrm{AF}(r=-0.472)$ and $\triangle \mathrm{C} 27 \mathrm{AE}(r=-0.365)$ in group $\mathrm{A} ; \triangle \mathrm{C} 27 \mathrm{AN}$ $(r=-0.313), \triangle \mathrm{C} 27 \mathrm{AF}(r=-0.310)$, and $\triangle \mathrm{C} 27 \mathrm{AE}(r=-0.546)$ in group $\mathrm{B}$; and $\triangle \mathrm{C} 27 \mathrm{AN}(r=-0.272), \Delta \mathrm{C} 27 \mathrm{AF}(r$ $=-0.426), \triangle \mathrm{C} 27 \mathrm{AE}(r=-0.449)$, and $\triangle \mathrm{C} 27 \mathrm{SVA}(r=0.305)$ in group $\mathrm{A}+\mathrm{B}$, respectively. In preoperative T1S, there were significant correlations with $\triangle \mathrm{C} 27 \mathrm{AN}(r=-0.427)$ and $\triangle \mathrm{C} 27 \mathrm{AE}(r=-0.451)$ in group $\mathrm{B}$; and $\triangle \mathrm{C} 27 \mathrm{AN}(r=-0.284)$ and $\triangle \mathrm{C} 27 \mathrm{AE}(r=-0.271)$ in group $\mathrm{A}+\mathrm{B}$, respectively. Detailed data are presented in Table 4. 
Table 4

Relationships between preoperative factors (age, C27ROM, and T1S) and changes of radiological parameters during postoperative 12 months

\section{Preoperative factors}

Age (years)

C27ROM ( $\left.{ }^{\circ}\right)$

T1S ( $\left.{ }^{\circ}\right)$

Group A (CSM)

$\triangle \mathrm{C} 27 \mathrm{AN}\left({ }^{\circ}\right)$

$-0.324$

$-0.252$

$-0.096$

$\triangle \mathrm{C} 27 \mathrm{AF}\left({ }^{\circ}\right)$

*0.391

**-0.472

$-0.098$

$\triangle \mathrm{C} 27 \mathrm{AE}\left({ }^{\circ}\right)$

$-0.268$

*-0.365

$-0.012$

$\triangle \mathrm{C} 27 \mathrm{ROM}\left({ }^{\circ}\right)$

0.146

$-$

$-0.042$

$\triangle \mathrm{T} 1 \mathrm{~S}\left({ }^{\circ}\right)$

0.017

$-0.017$

$\triangle \mathrm{C} 27 \mathrm{SVA}(\mathrm{mm})$

$-0.240$

$\star 0.351$

$-0.052$

Group B (OPLL)

$\triangle$ C27AN $\left({ }^{\circ}\right)$

$-0.059$

*-0.313

$\star \star-0.427$

$\triangle \mathrm{C} 27 \mathrm{AF}\left({ }^{\circ}\right)$

0.222

*-0.310

0.285

$\triangle \mathrm{C} 27 \mathrm{AE}\left({ }^{\circ}\right)$

0.055

**-0.546

**-0.451

$\triangle \mathrm{C} 27 \mathrm{ROM}\left({ }^{\circ}\right)$

0.221

-

$-0.238$

$\triangle \mathrm{T} 1 \mathrm{~S}\left({ }^{\circ}\right)$

$-0.171$

$-0.267$

$\triangle \mathrm{C} 27 \mathrm{SVA}(\mathrm{mm})$

$-0.265$

0.172

$-0.201$

\section{Group A + B}

$\begin{array}{llll}\triangle \mathrm{C} 27 \mathrm{AN}\left({ }^{\circ}\right) & -0.188 & *-0.272 & *-0.284 \\ \triangle \mathrm{C} 27 \mathrm{AF}\left(^{\circ}\right) & * 0.293 & * *-0.426 & 0.119 \\ \triangle \mathrm{C} 27 \mathrm{AE}\left(^{\circ}\right) & -0.096 & * *-0.449 & *-0.271 \\ \triangle \mathrm{C} 27 \mathrm{ROM}\left({ }^{\circ}\right) & 0.174 & - & -0.143 \\ \triangle \mathrm{T} 1 \mathrm{~S}\left({ }^{\circ}\right) & -0.081 & -0.093 & - \\ \triangle \mathrm{C} 27 \mathrm{SVA}(\mathrm{mm}) & *-0.236 & * 0.305 & -0.147\end{array}$

Pearson correlation coefficient $(r)$ was used to assess the relationship. CSM cervical spondylotic myelopathy; OPLL ossification of posterior longitudinal ligament; C27AN C2-7 Cobb angle in neutral; C27AF C2-7 Cobb angle in flexion; C27AE C2-7 Cobb angle in extension; C27ROM C2-7 range of motion; T1S T1 slope; C27SVA C2-7 sagittal vertical axis; * $p<0.05$; * * $p<0.01$ 
Table 5

Functional outcomes

Group A (CSM) Group B (OPLL) Total (Group A+B)

p value ${ }^{+}$

Preoperative

\begin{tabular}{lllll} 
mJOA score & $10.94 \pm 2.08$ & $11.26 \pm 1.85$ & $11.12 \pm 1.94$ & 0.487 \\
\hline Nurick grade & $3.06 \pm 0.95$ & $2.93 \pm 0.77$ & $2.99 \pm 0.85$ & 0.507
\end{tabular}

Postoperative (12 months)

\begin{tabular}{lllll} 
mJOA score & $* 14.13 \pm 1.29$ & $* 14.49 \pm 1.39$ & $* 14.33 \pm 1.35$ & 0.251 \\
\hline Nurick grade & $* 1.97 \pm 0.65$ & $* 1.81 \pm 0.66$ & $* 1.88 \pm 0.66$ & 0.316 \\
\hline Recovery rate $(\%)$ & $41.17 \pm 27.73$ & $45.53 \pm 20.34$ & $43.67 \pm 23.70$ & 0.435
\end{tabular}

CSM cervical spondylotic myelopathy; OPLL ossification of posterior longitudinal ligament; mJOA modified Japanese Orthopedic Association; ${ }^{+}$between groups A and B; * Significant difference compared to preoperative data $(p<0.05)$

5. Inter-observer reliability

Regarding radiological parameters, inter-observer reliability presented as ICC showed very good agreement, ranging from 0.80 to 0.99 . The final radiologic parameters were used with the average of two investigator's measurements.

\section{Functional Outcome}

There were no significant differences in preoperative mJOA score $(10.94 \pm 2.08$ vs. $11.26 \pm 1.85, p=$ $0.487)$ and Nurick grade ( $3.06 \pm 0.95$ vs. $2.93 \pm 0.77, p=0.507)$ between groups A and B. Postoperatively, there were also no statistical significant differences in postoperative mJOA score (14.13 \pm 1.29 vs. 14.48 $\pm 1.39, p=0.251)$, Nurick grade $(1.97 \pm 0.65$ vs. $1.81 \pm 0.66, p=0.316)$, and the recovery rate $(41.17 \pm$ $27.73 \%$ vs. $45.53 \pm 20.34 \%, p=0.435$ ) between the two groups. Detailed data are presented in Table 4 .

\section{Discussion}

Studies about the differences in radiological and functional outcomes between patients with OPLL and CSM after laminoplasty are scarce. Herein, we focused firstly on the changes in cervical lordosis, ROM, and SVA in radiological outcomes. Sakai et al. [6] and Lee et al. [7] reported that both cervical lordosis and SVA worsened following laminoplasty in both CSM and OPLL groups, while Sakaura et al. [8] and Kato et al. [9] reported no significant differences of cervical lordosis and SVA after laminoplasty in both CSM and OPLL groups. Our results were inconsistent with the results of these previous studies. The CSM group showed a significant increase of C27SVA at the 12-month follow-up, but there was no significant difference in the OPLL group. Additionally, there was a slight loss of cervical lordosis, with no statistical 
significance, in both groups. Considering the changes in radiological parameters, there was a deterioration of sagittal balance with increase of C27SVA in the CSM group compared to the OPLL group after multi-level laminoplasty.

There was a significant reduction in ROM at 12 months after laminoplasty in both groups, and the CSM group showed a greater reduction of ROM than the OPLL group. Some previous reports have described a reduction in ROM as well as a progression of sagittal imbalance after laminoplasty, but the etiology of these problems remain debatable $[10,11]$. The damage and atrophy of the posterior deep muscles including the semispinalis cervicis muscle, injury of the nuchal ligament, and bony fusion of facet joints after laminoplasty are considered the main reasons for these postoperative changes [12-14]. The reduction in ROM following laminoplasty is reported to range from $30-70 \%$ of the preoperative ROM [1517]. Seichi et al. [12] reported a reduction in ROM from $13^{\circ}$ to $47^{\circ}$ in CSM patients. Our study showed a postoperative reduction of approximately $30 \%$ in the CSM group and $20 \%$ in the OPLL group. The smaller preoperative ROM of the OPLL group compared to the CSM group may have originated from the stiffed segments with calcification of the posterior longitudinal ligaments. As a result, we expect that postoperative deterioration of sagittal balance in the OPLL group would be less than that of the CSM group after laminoplasty. In addition, Hyun et al. [18] reported a small ROM in OPLL after laminoplasty than in CSM (47.2\% vs. $72.7 \%$ of preoperative ROM) because of the postoperative higher frequency of laminar auto-fusion in OPLL than in CSM.

It is necessary to consider the effect of age on the development of sagittal imbalance with kyphotic change. Sakai et al. [19] reported that advanced age was a risk factor for kyphotic deformity after laminoplasty in CSM patients with normal preoperative sagittal alignment. In the thoracolumbar spine, a decrease of lumbar lordosis and an increase of thoracic kyphosis are associated with increasing age, which results in increased SVA as an indicator of the sagittal global balance [20-22]. However, unlike the thoracolumbar spine, the sagittal balance of the cervical spine is relatively well maintained in elderly patients because of increased cervical lordosis as a compensatory mechanism [23]. To maintain the lordotic curvature of the cervical spine in the condition with sagittal imbalance, it is necessary to preserve and enhance the strength of the cervical extensor muscles. There are several less-invasive methods for saving cervical posterior structures to maintain cervical lordosis after laminoplasty [19]. However, it is generally assumed that extensor muscles already show age-related degradation in elderly patients, which will worsen the deterioration of the cervical extension mechanism postoperatively.

The age-related cervical ROM and curvature should also be evaluated in asymptomatic individuals. Yukawa et al. [24] reported that the cervical motions (flexion, extension, and total range) and the curvature of neutral neck posture were $25.5^{\circ} \pm 9.5^{\circ}, 16.2^{\circ} \pm 9.4^{\circ}, 41.8^{\circ} \pm 12.7^{\circ}$, and $18.4^{\circ} \pm 11.6^{\circ}$ in male, and $26.3^{\circ}$ $\pm 98.4^{\circ}, 26.7^{\circ} \pm 8.8^{\circ}, 53.0^{\circ} \pm 10.9^{\circ}$, and $16.9^{\circ} \pm 10.8^{\circ}$ in female patients in their sixties, respectively, which was the average age of our patients. These results show a greater range of flexion and similar cervical lordosis than the preoperative parameters of our patients. With increasing age, there was decreased ROM and increased cervical lordosis, and the range of extension decreased more than the flexion. These results show that cervical lordosis naturally increases and the range of extension decreases with aging caused 
by compensatory mechanism in asymptomatic individuals. This phenomenon was different from our postoperative radiological findings including the reduction of both ROM and cervical lordosis. Especially, the effects of age for $\triangle \mathrm{C} 27 \mathrm{AF}$ (positive correlation) and $\triangle \mathrm{C} 27 \mathrm{SVA}$ (negative correlation) were limited, and the final result showed a significant decrease of cervical flexion and increase of SVA compared to no significant difference in cervical extension 12-month postoperatively.

Few studies have focused on restriction of each cervical flexion or extension after laminoplasty, although many studies have reported a reduction in overall ROM with loss of cervical lordosis. Suk et al. [2] reported significant restriction in both flexion and extension, while Hyun et al. [16] showed restriction in flexion but not in extension. However, these results did not highlight any differences between the CSM and OPLL groups. Our results showed significantly more restriction of cervical flexion in the CSM group than the OPLL group after laminoplasty. With a reduction in overall ROM, the composition of ROM, comprising flexion and extension, changed from 1:2 to 1:3 postoperatively in the CSM group; however, there was no change in the OPLL group. We believe that the reason for restriction of cervical flexion primarily observed in the CSM group after laminoplasty is the compensatory mechanism against the progression of sagittal imbalance caused by a postoperative dysfunction of cervical posterior structures. In other words, a reduction of ROM with distinct restriction of cervical flexion has occurred to correct the sagittal imbalance in which the center of gravity of the head leans forward with loss of cervical lordosis and increase of SVA (Fig. 2).

In addition to age, the effect of preoperative T1S should be also considered to evaluate the radiological outcomes after laminoplasty between the CSM and OPLL groups. The preoperative high T1S is already known to be an important factor related to the development and deterioration of sagittal imbalance after laminoplasty $[3,4]$. In our study, T1S showed no significant differences between the two groups pre- and postoperatively. There were no significant correlations between T1S and the changes in radiological parameters in the CSM group. However, higher preoperative T1S was related to restricted cervical extension and loss of cervical lordosis postoperatively in the OPLL group. In a comprehensive review of the effects of age, ROM, and T1S; we expect that C27ROM, unlike age and T1S, is affected mainly by the dysfunction of posterior cervical structures. The effect of posterior surgery with the damages of posterior extensor muscles and ligaments are bigger in the CSM group presenting greater preoperative ROM, which led to the increase of SVA. The reduction of ROM is also thought to be involved in the compensatory mechanism as mentioned above. Unfortunately, the compensatory mechanism related with reduction of ROM in the CSM group was insufficient to protect deterioration of sagittal balance with increasing SVA, even though it minimized loss of cervical lordosis. However, the stiffed and less-flexible segments with the formation of ossification of the posterior longitudinal ligaments combined with a compensatory mechanism of ROM preserved SVA and cervical lordosis in the OPLL group.

Unfortunately, the long-term changes in ROM and cervical curvature could not be determined from the 12month follow-up study; thus, these can be predicted indirectly by referring to the results of previous studies. Kawaguchi et al. [17] reported a rapid decrease in ROM within the first year following surgery, and no further decreases thereafter without distinction between the CSM and OPLL groups. Hyun et al. [18] 
reported the differences in the reduction of ROM between the CSM and OPLL groups. The OPLL group showed a continuous reduction of ROM for 5 years; however, there was a recovery after initial reduction for 2 years in the CSM group. However, there were no significant differences in functional outcomes depending on the radiological changes. In our results, we found significant improvements in functional outcomes in the CSM and OPLL groups with no significant differences 12 months postoperatively. When considering these favorable functional outcomes, the radiological changes including the reduction of ROM and increase of SVA in the CSM group can be regarded as meaningless. However, we think that careful observation is required even after 12 months when considering the greater deterioration of sagittal balance in the CSM group than in the OPLL unlike the results of previous literature.

Our study has several limitations. First, it was a retrospective study with a relatively small number of participants. Second, the 12 months follow-up period was quite short to expect to observe overall changes in postoperative sagittal balance. Third, there was no consideration of whole-spine sagittal balance, which can influence cervical sagittal balance. Further studies with a larger number of participants during the long-term follow-up period are required to demonstrate the exact radiological and clinical differences between CSM and OPLL groups.

\section{Conclusion}

Although there were no significant differences in functional outcomes, the CSM group showed a greater deterioration of sagittal balance with a significant increase of C27SVA after multi-level laminoplasty than the OPLL group. We consider that the stiffness and less-flexible segments of OPLL with the reduction of ROM as a compensatory mechanism prevented deterioration of sagittal balance with preserving SVA and cervical lordosis. Additional careful observations are required considering these radiological and structural differences between the CSM and OPLL groups.

\section{Abbreviations}

CSM

Cervical spondylotic myelopathy

OPLL

Ossification of the posterior longitudinal ligament

C27AN

C2-7 Cobb angle in neutral neck posture

C27AF

$\mathrm{C} 2-7 \mathrm{Cobb}$ angle in flexed neck posture

C27AE

C2-7 Cobb angle in extended neck posture

C27ROM

C2-7 range of motion

T1S 
T1 slope

C27SVA

C2-7 sagittal vertical axis

mJOA score

modified Japanese Orthopedic Association score

\section{Declarations}

\section{Ethics approval and consent to participate}

All procedures performed in studies involving human participants were in accordance with the ethical standards of the institutional and/or national research committee and with the principles of the 1964 Declaration Helsinki and its later amendments or comparable ethical standards. Written informed consent was waived due to retrospective study design under the approval of the Institutional Review Board, Yeungnam University Hospital (No. 2020-03-003).

\section{Availability of data and materials}

The datasets during and/or analysed during the current study are available from the corresponding author on reasonable request.

\section{Competing interests}

The authors declare that they have no competing interests.

\section{Funding}

This work was supported by the National Research Foundation of Korea (NRF) grant funded by the Korea government (MSIP; Ministry of Science, ICT \& Future Plan (NRF-2019M3E5D1A02068142), which involved in the design of the study and collection, analysis, and interpretation of data as well as the manuscript.

\section{Authors' contributions}

IJ was the principal clinician who planned the entire evaluation and procedure.

IJ and DY participated in the coordination and data collection/interpretation for the study.

SWK was advisor for the procedure.

All authors have read and approved the manuscript. 


\section{Acknowledgements}

Not applicable.

\section{References}

1. Hirabayashi K, Watanabe K, Wakano K, Suzuki N, Satomi K, Ishii Y. Expansive open-door laminoplasty for cervical spinal stenotic myelopathy. Spine (Phila Pa 1976). 1983;8:693-9.

2. Suk KS, Kim KT, Lee JH, Lee SH, Lim YJ, Kim JS. Sagittal alignment of the cervical spine after the laminoplasty. Spine (Phila Pa 1976). 2007;32:E656-60.

3. Kim TH, Lee SY, Kim YC, Park MS, Kim SW. T1 slope as a predictor of kyphotic alignment change after laminoplasty in patients with cervical myelopathy. Spine (Phila Pa 1976). 2013;38:E992-7.

4. Lin BJ, Hong KT, Lin C, Chung TT, Tang CT, Hueng DY, et al. Impact of global spine balance and cervical regional alignment on determination of postoperative cervical alignment after laminoplasty. Medicine. 2018;97:e13111.

5. Hirabayashi K, Miyakawa J, Satomi K, Maruyama T, Wakano K. Operative results and postoperative progression of ossification among patients with ossification of cervical posterior longitudinal ligament. Spine (Phila Pa 1976). 1981;6:354-64.

6. Sakai K, Yoshii T, Hirai T, Arai Y, Shinomiya K, Okawa A. Impact of the surgical treatment for degenerative cervical myelopathy on the preoperative cervical sagittal balance: a review of prospective comparative cohort between anterior decompression with fusion and laminoplasty. Eur Spine J. 2017;26:104-12.

7. Lee $\mathrm{CH}$, Jahng TA, Hyun SJ, Kim KJ, Kim HJ. Expansive Laminoplasty Versus Laminectomy Alone Versus Laminectomy and Fusion for Cervical Ossification of the Posterior Longitudinal Ligament: Is There a Difference in the Clinical Outcome and Sagittal Alignment? Clin Spine Surg. 2016;29:E9-15.

8. Sakaura H, Ohnishi A, Yamagishi A, Ohwada T. Differences in Postoperative Changes of Cervical Sagittal Alignment and Balance After Laminoplasty Between Cervical Spondylotic Myelopathy and Cervical Ossification of the Posterior Longitudinal Ligament. Global Spine J. 2019;9:266-71.

9. Kato M, Namikawa T, Matsumura A, Konishi S, Nakamura H. Effect of Cervical Sagittal Balance on Laminoplasty in Patients With Cervical Myelopathy. Global Spine J. 2017;7:154-61.

10. Ratliff JK, Cooper PR. Cervical laminoplasty: a critical review. J Neurosurg. 2003;98:230-8.

11. Satomi K, Nishu Y, Kohno T, Hirabayashi K. Long-term follow-up studies of open-door expansive laminoplasty for cervical stenotic myelopathy. Spine (Phila Pa 1976). 1994;19:507-10.

12. Seichi A, Takeshita K, Ohishi I, Kawaguchi H, Akune T, Anamizu Y, et al. Long-term results of doubledoor laminoplasty for cervical stenotic myelopathy. Spine (Phila Pa 1976). 2001;26:479-87.

13. Takeuchi K, Yokoyama T, Ono A, Numasawa T, Wada K, Kumagai G, et al. Cervical range of motion and alignment after laminoplasty preserving or reattaching the semispinalis cervicis inserted into axis. J Spinal Disord Tech. 2007;20:571-6. 
14. Umeda M, Sasai K, Kushida T, Wakabayashi E, Maruyama T, Ikeura A, et al. A less-invasive cervical laminoplasty for spondylotic myelopathy that preserves the semispinalis cervicis muscles and nuchal ligament. J Neurosurg Spine. 2013;18:545-52.

15. Hase $H$, Watanabe $T$, Hirasawa $Y$, Hashimoto H, Miyamoto $T$, Chatani $K$, et al. Bilateral open laminoplasty using ceramic laminas for cervical myelopathy. Spine (Phila Pa 1976). 1991;16:126976.

16. Hyun SJ, Rhim SC, Roh SW, Kang SH, Riew KD. The time course of range of motion loss after cervical laminoplasty: a prospective study with minimum two-year follow-up. Spine (Phila Pa 1976). 2009;34:1134-9.

17. Kawaguchi Y, Kanamori M, Ishihara H, Ohmori K, Nakamura H, Kimura T. Minimum 10-year followup after en bloc cervical laminoplasty. Clin Orthop Relat Res. 2003:129-39.

18. Hyun SJ, Riew KD, Rhim SC. Range of motion loss after cervical laminoplasty: a prospective study with minimum 5-year follow-up data. Spine J. 2013;13:384-90.

19. Sakai K, Yoshii T, Hirai T, Arai Y, Torigoe I, Tomori M, et al. Cervical Sagittal Imbalance is a Predictor of Kyphotic Deformity After Laminoplasty in Cervical Spondylotic Myelopathy Patients Without Preoperative Kyphotic Alignment. Spine (Phila Pa 1976). 2016;41:299-305.

20. Park MS, Moon SH, Lee HM, Kim SW, Kim TH, Lee SY, et al. The effect of age on cervical sagittal alignment: normative data on 100 asymptomatic subjects. Spine (Phila Pa 1976). 2013;38:E458-63.

21. Sugrue PA, McClendon J Jr, Smith TR, Halpin RJ, Nasr FF, O'Shaughnessy BA, et al. Redefining global spinal balance: normative values of cranial center of mass from a prospective cohort of asymptomatic individuals. Spine (Phila Pa 1976). 2013;38:484-9.

22. Yoshida G, Yasuda T, Togawa D, Hasegawa T, Yamato Y, Kobayashi S, et al. Craniopelvic alignment in elderly asymptomatic individuals: analysis of 671 cranial centers of gravity. Spine (Phila Pa 1976). 2014;39:1121-7.

23. Kawai S, Sunago K, Doi K, Saika M, Taguchi T. Cervical laminoplasty (Hattori's method). Procedure and follow-up results. Spine (Phila Pa 1976). 1988;13:1245-50.

24. Yukawa Y, Kato F, Suda K, Yamagata M, Ueta T. Age-related changes in osseous anatomy, alignment, and range of motion of the cervical spine. Part l: Radiographic data from over 1,200 asymptomatic subjects. Eur Spine J. 2012;21:1492-8.

\section{Figures}




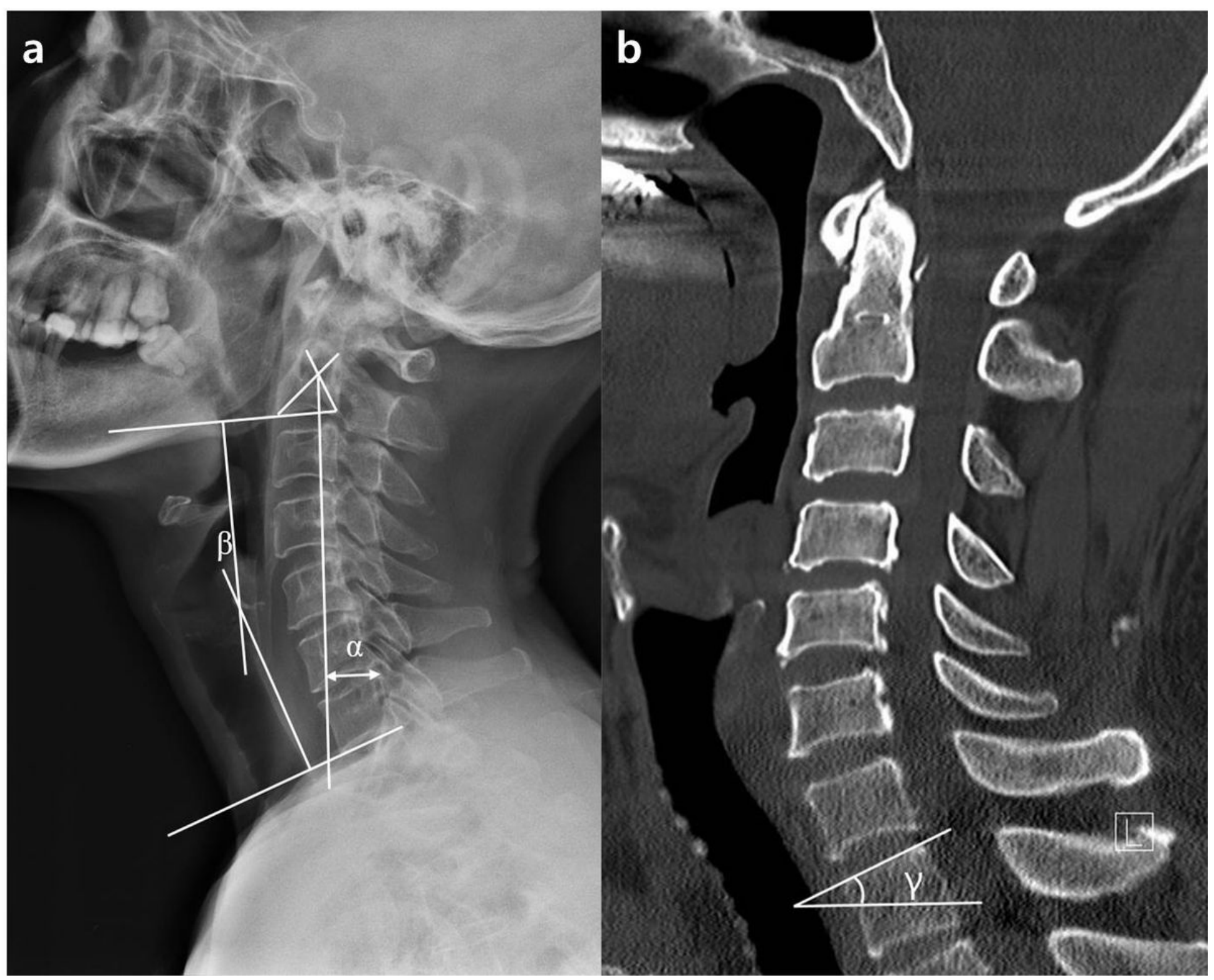

Figure 1

Measurement of $\mathrm{C} 2-\mathrm{C} 7$ sagittal vertical axis (a) and $\mathrm{C} 2-\mathrm{C} 7 \mathrm{Cobb}$ angle $(\beta)$ on lateral radiograph (a), and T1 slope ( $\mathrm{Y}$ ) on sagittal view of computed tomography (b). 


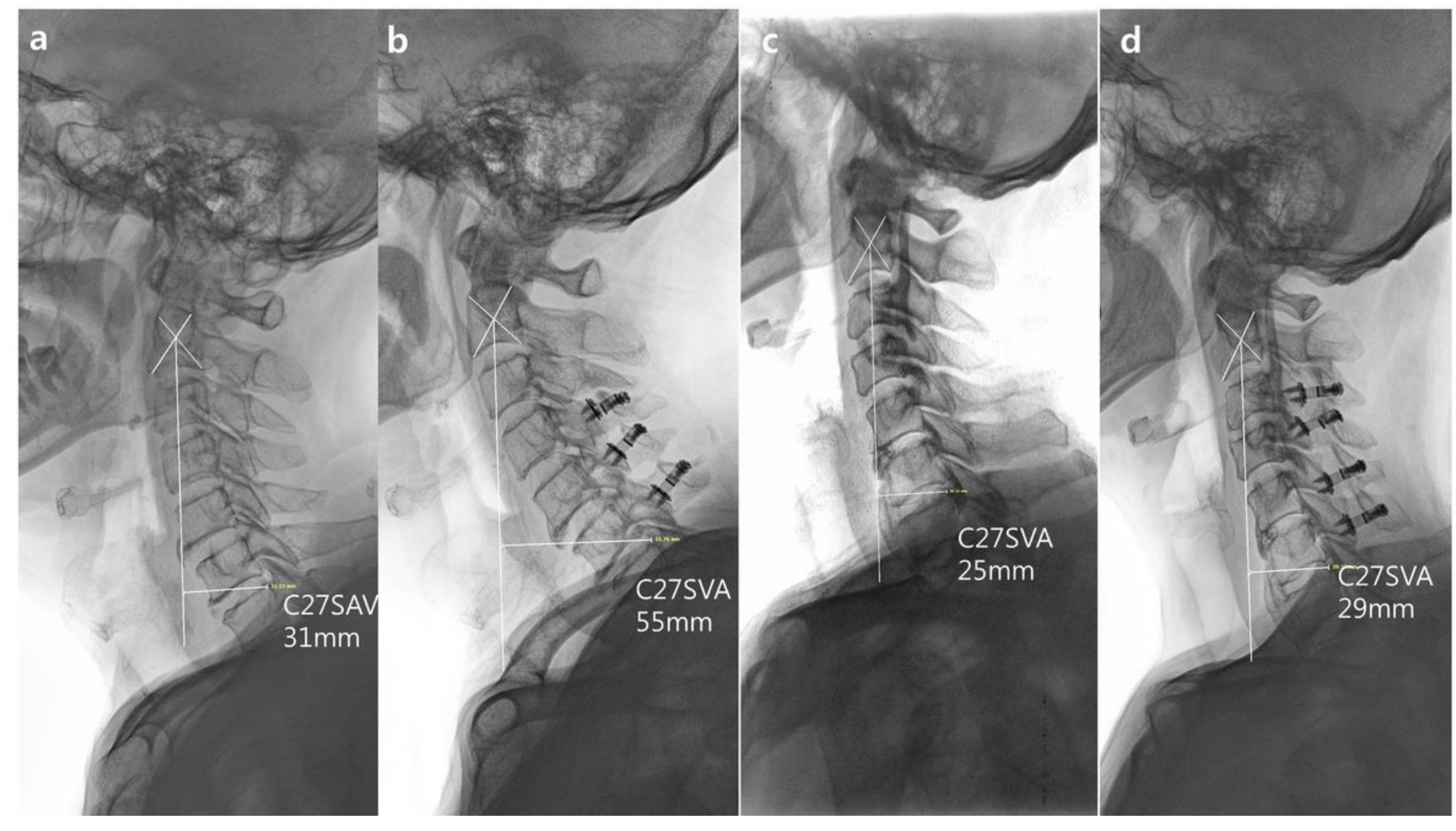

Figure 2

Changes in cervical lordosis and sagittal balance pre-and postoperatively. In the CSM patient, the preoperative lateral radiograph showed preserved cervical lordosis and sagittal balance (a). There was increased C27SVA despite maintained cervical lordosis on the postoperative lateral radiograph (b). In OPLL patients, there were no significant differences between pre- (c) and post- (d) operative lateral radiographs. Both the cervical lordosis and sagittal balance were maintained. 